\title{
Effect of the Motor Game "Exchequer Points" on the Topological Structure of the Relational Space: Case of 7 - 8 Aged Tunisians Pupils
}

\author{
Anis Ben Chikha, Nizar Guemri, Liwa Masmoudi, Nizar Souissi \\ Department of Education Sciences and Pedagogy, Higher Institute of Sport and Physical Education, Tunis, Tunisia \\ Email: benchikhaanis@yahoo.fr
}

Received 13 May 2015; accepted 4 July 2015; published 7 July 2015

Copyright (C) 2015 by authors and Scientific Research Publishing Inc.

This work is licensed under the Creative Commons Attribution International License (CC BY).

http://creativecommons.org/licenses/by/4.0/

(c) (i) Open Access

\begin{abstract}
The relational structure of the space for the child in order to ensure an efficient interaction with its environment is crucial. A didactic approach has as base that motor game could improve systemic and sensory-motor function of the body. The acquisition of a topological and spatial language represents the perspective of this study, in particular based on the action of a game created about it and we have called "Exchequer points". The effects of this game on the topological relationships were studied among students $(\mathrm{N}=44)$ of second primary school during the school year 2014-2015. The average age of the participants is 7.3 years. ANOVA model for repeated measures was used for data analysis. Results showed that after the learning program based on the motor game, the children of the experimental group $(\mathrm{N}=22)$ significantly improved their topological relationships assessment. On the contrary, the children of the control group $(\mathrm{N}=22)$ did not show significant differences between the pre- and post-measurement.
\end{abstract}

\section{Keywords}

Spatial Relations, Transfer, Motor Game

\section{Introduction}

Space is the physical, perceptual, conceptual or representative in which real or represented objects, mobile or immobile, animated ornot animated, are located and moved actively or passively, in a system of spatio-temporal relations (Fayasse \& Thibaut, 2003). For this purpose, whether in motor activities or even in the activities of 
daily life the child's motor skills require precise knowledge of the position and orientation of the body and objects in the space where he acts. In a spatio-temporal reference system, dimensional and relational aspects of space need to be accurately defined to promote motor cognition and so appropriate behaviour (Wade \& Swanston, 2001). Consequently, an essential role of spatial perception is to provide access to information for the organization of the action (Milner \& Goodale, 1995). In this context, the surrounding world can only be understood in the mode of a possible overall action (Gibson, 1979).

This process led to a functional definition of spatial perception (Previc, 1998). The perceived space is discontinuous, particularly structured according to the body's capacity for action that dependent on object properties and perceived benchmarks that they defined it (Neggers \& Bekkering, 2000).

In this study we have chosen to use the game in its functional spatial dimension, to arrive at a rational and efficient structuring of childhood environment. Indeed, the child's actuation in a fun location space exploration would be our interest. It is a complex situation that he has to find each time the suitable solution tailored to the proposed variables through perceptual mechanisms of space navigation. This capacity is then based on complex mechanisms which, if they do not develop properly, make complicated or impossible processing visuospatial information, that joined what (Paoletti, 1999) was defined as motor education. So, there is an approach that emphasizes the use of driving experiences on a daily basis by the child as a key to self-knowledge and a move towards the objective and rational thought. This educational approach is in line with the idea that the driving experience or well-structured games allow children to discover general and disciplinary concepts (Paoletti, 1999).

\subsection{Visual Perception of Space}

In the context of visual and spatial apprehension of space, the existence of several visual processing steps is consistent with the model of Marr (1982), which proposes an organization of perception in several successive stages building. The visual percept from the retinal image, very informative, to the object in three identified dimensions. This model is supported by the hierarchical and anatomical patterning visual cortical areas, which carry out treatment of more complex visual information (Felleman \& Van Essen, 1991; Young, 2000). The visual information mechanisms processing are described as being more likely inferential, based on Bayesian principles of integration (Rao \& Ballard, 1999). The most useful information would not be present at the retinal level, but within the visual information processing system (Scannell \& Young, 1999): internal knowledge about how the world is structured contributes to process incoming visual signals. This framework allows considering treatment of spatial information is also based on internal knowledge: representations of the body and the body's capacity for action. Computation approaches to motor intentional indeed postulate that the movement and its effects on the environment would be decisive for the structuring of sensory-motor invariants. The co-occurrence of motor and sensory signals during motor production would indeed build internal representations of expected sensory consequences of intentional acts engines (Mossio \& Taraborelli, 2008). This knowledge allows later to give a motor direction or a driving intention to intentional motor acts observed (Bidet-Ildéi, Orliaguet, \& Coello, 2011). This sensory-motor knowledge would also perceive the space in relation to the organization of potentials actions. Visual information would then be processed in the cortex by the dorsal route Ungerleider \& Mishkin (1982). This occipito-parietal pathway is specialized in visuospatial processing information (path of “where?”), as opposed to the occipito-temporal channel (path “what?"). It is considered by Jeannerod $(1994,2003)$ as a "path of action". The processing of visuospatial information would be primarily located in the posterior parietal regions of the right cerebral cortex (Aleman et al., 2002). It is therefore crucial to the spatial location and visual guidance movement in space, and selectively responds to the spatial aspects of stimuli such as the direction or speed (Ungerleider, Courtney, \& Haxby, 1998). According to this view, the visual system would be divided into two independent subsystems, one ventral, dedicated to the vision for the collection, and the other back, dedicated to the vision for action (Goodale \& Milner, 1992; Milner \& Goodale, 1995).

\subsection{Spatial Cognitive Map and Spatial Representation}

Visual perception then alienates the skills and basic facilities necessary for an autonomous locomotion, effective and safe in the physical and social environment. It allows us to become aware of our position and update information from the environment. Indeed, according to many authors (Gärling, 1995; Gärling, Book, \& Lindberg, 1984; Russell \& Ward, 1982), an awareness of the acquired and stored environment plays an important role on people accessing the skill to plan and accomplish their movements. 
A significant amount of research has been conducted on the spatial aspects of mental models. As a result of this research, it was shown that individuals are able to build a spatial mental model that not only contains benchmarks, but also information on the properties and geometric relationships of this space called a "cognitive map” (Doré \& Mercier, 1992). This connotation refers as defined by Tolman (1948), an internal representation of the surrounding space. Thus, the spatial representation is then based on three prerequisites: Cognitive processing environment (individual knowledge of a specific environment), spatial abstraction (ability to manipulate abstract concepts such as spatial topological relations) and the ability to represent space in the form of cognitive maps (Pierre \& Soppelsa, 1998). In fact, it glosses two distinct spatial representations: a general representation (card type), and a representation paths (card road) illustrating that there are different strategies for knowledge of space. The strategy used in the card type and card road has specific features whose origins are found in different frames of reference used: egocentric (type road) and allocentric (card type).

\subsection{The Spatial Egocentric and Allocentric References}

The egocentric reference constitutes one of the bases of the organization of the oriented behaviour extracorporeal space (Jeannerod, 2006; Jeannerod \& Biguer, 1987). In other words, the perception of the spatial position of objects to which movements are directed can be determined with respect to some or all of our body. To this end, locating the ability points of the body grows together with the ability to use his body to move and to guide. The human body is a fundamental axis system in orientation phenomena. It will be noted that the lateral axis (or median) which refers to the symmetrical sides of the body, the front axle will be given by the different functions of the body (the look direction in particular) and the vertical axis (cephalo-caudal) expressed by gravity, which may be detected in a standing position. Different terminology in the literature can thus be used to state the origin of egocentric coding. The egocentric encoding of an object can be retinoids-or eye-centered, cerebro-centered (Karn et al., 1997), trunk-centered (Darling \& Miller, 1995), referred to a specific body segment to the task as requested shoulder (Soechting et al., 1990), or referred to the viewing direction. At each of these tasks corresponds an egocentric reference frame with different origin body (Ghafouri et al., 2002).

Instead, the card type of representation is based on knowledge of the topographical properties of the environment, such as the location of objects relative to a fixed coordinate allocentric system. It is therefore an untied representation of the position of the individual. His role is predominant in the browser's ability to determine the direction of places outside of his field of vision or establish spatial relationships between places whose links have not previously been explored physically. The provision of a card-type description is often hierarchical type, that is to say, the space is divided into separate areas, and each area is described one after another. The card type, unlike the typical representation road, addresses a reorganization of information such as detours, shortcuts, etc... (O'Keefe \& Nadel, 1976). Moreover, the superiority of the representation of the card type on the representation of the road type is confirming at an experimental level. Certainly, much research has been aimed at finding whether spatial representations built on the basics of navigation (e.g. from a road perspective type) have the same metric properties that representations using a map token (card-type perspective). To this end, Noordzij \& Postma (2005) have established a bird flight distance comparison task. This experiment required participants to adopt an aerial perspective in agreement with the card type description and not consistent with the description type of road. The results show the superiority of the card type description on the type road description. This methodology has been reused in subsequent research as Péruch, Chabanne, Nese, Thinus-Blanc \& Denis (2006) set up an experiment in which participants are asked to mentally compare the distances between different objects. In a first experiment, the two distances compared have the same starting point, when in a second experiment the starting points were different. In both cases, a greater number of correct answers and a shorter response time are observed from a perspective map type. From these results it was reported that the estimation of distances is easier when spatial representations were constructed from a description type map that from a road description type of a complex space.

The ability to use multiple reference systems and switch from one to another in accordance with the required tasks and information, contained signs the acquisition of a stable reference system. According Wohlwill (1981), the kind of reference system used by an individual depends on various situational factors such as the presence or absence of salient landmarks, the demand for a particular task and probably personal experience. The ability of the child following the acquisition of a permanent referential to orient spatially relates to analytical skills and understanding between the marks visually perceived, as well as the ability to stay focused after change of position markers or his own body (Barisnikov \& Pizzo, 2007). So it is right to point out the importance of the game 
engine in all situations and motor behaviour that could offer for the child to best explore its spatial potential. In fact, it allows children to use their creativity while developing their imagination, dexterity, and physical, cognitive and emotional potential. Education professionals and child development agree that the game provides the child with movement experiences, creativity, and friendship in a way that emphasizes fun (Lester \& Russell, 2011). In addition, the game is important for the harmonious development of the brain (Ginsburg, 2007). The game also promotes a significant increase in physical activity (Tucker, 2008). A survey in the United States (Healthy Schools for Healthy Kids) among 500 teachers and 800 parents' indicates that 90\% of teachers and $86 \%$ of parents believe that active children learn better and behave better in class. Ginsburg (2007) points out that the game is considered as a great way to increase the level of motor activities for children, and that is the joy of childhood. In accordance with the theoretical basis presented above we have developed a quasi-experimental research to explore the effect of a playful driving education program designed for the development of thematic concepts related to topological representations of space and which are transverse to other academic skills with potential positive influence on children.

\section{Method}

This study is about a game that we created and called “Exchequer points”. The game aimed the child's motor learning taking into account internal and external factors that influence the acquisition of actions and spatial displacements representations, programming, organizing trips, place and time, retroactive and proactive feedback, attention and memory. Certs, these skills could support following a transfer of learning, the development of transversal skills useful in other educational tasks such as handwriting, geometry etc... The motor education facilitates, similarly, the development of school disciplinary skills including not only math, native language, but also awakened in fine arts and music (Wauters-Krings, 2009).

The game is a grid drawn, on the floor in a primary school playground, with white paint, measured 12 meter by 12 meter with49 black points on each intersection. It takes place on a large square divided into 36 squares other form of chess. This game would mainly target the spatial organization through actuating the children's ability to be in the area to determine the position one occupies in relation to benchmarks and a coordinate system and matching correctly different movements for different topological possible relations and described by the various proposed variants. Spatial orientation is associated with the perception and spatial structure is associated with abstraction and reasoning.

Through the experiment on the principles of the game "points Exchequer" we will test, during the first term of school year 2014-2015, the development of spatial relationships of the child regardless of the reference system.

\subsection{Participants}

Forty four students had voluntary participated in this study. They are schooled in both mixed classes of second year of primary school each one containing twenty two student. The classes belong to the same public school and with two different teachers. But we chose two teachers with the same basic training and with the same number of years' experience. To this end, we arrange to work with an experimental group and a control group.

The average age of the participants is 7.3 years. These children attend a public primary school. Their middle parent socio-cultural level is defined by the father's job. All these participants are considered normal and welladjusted to schooling. They are all in the classes corresponding to their chronological age and are average students for all school subjects. Their parents were informed and give their agreement signature about the participation of their children in the experiment research and they have the opportunity at any time to withdraw their children from it. The results of this research guarantee anonymity and confidentiality and the parents may be aware of their children's skills assessment.

\subsection{Procedure}

This study is therefore divided into three parts. First, we conducted a pre-test on two groups of children $\left(2^{\text {nd }}\right.$ year of primary school) to verify the homogeneity of the sample and a test assessing their topological relationships. Secondly, and for 12 weeks, with two sessions of 50 minutes/week, we submitted on one hand, the experimental group learning with a program based on the game and on the other, the control group with a conventional learning. The third and final section is devoted to a re-test evaluating the topological relations of the two groups of students. 
The test done for the children to assess the topological relationships is: RTD (Topological and Directional Relation Test by Barry (2010). In fact, for the test, the child is interviewed individually in a room of his school in which he is sitting comfortably at a table facing the examiner. The child should then follow a presentation by 9 points initially listed on a sheet "refer" which is laid flat on the table and oriented in portrait, try to recognize the place of a single item on a separate sheet "stimulus". After passing reference to right over, the examiner inverts reference sheet and stimulus leaves and starts executing it, refer to the left.

3 types of responses are recorded:

-Correct answer

-Mirroring answer: the child shows the symmetrical point to the expected relative to a vertical axis passing through the centre of the sheet.

-Error: any response not corresponding to a right answer or a mirror.

The correct answer is separated from the total number of errors and the number of mirrors depending on the side of the sheet "referent" so it has 4 results, two for the referent right (total errors and total mirrors) and two for the referent left (total errors and total mirrors). Using the calibration tables, the corrector converts the raw results in cumulative percentages to compare the results of the participant with those of children in the same age. Having collected the data obtained, we subject them to analysis of variance (ANOVA).

\subsection{Data Analysis}

For each measurements taken before and after training, ANOVA was performed with the factor "type of learning” (motor game learning and traditional learning) as a variable factor inter and “period” (pre-test and post-test) as a variable intra. The factorial model was $2 \times 2$ ( 2 groups $\times 2$ measurements). Post-hoc comparisons were made with the Sidak test and the level of significance was set at $\alpha=0.05$.

\section{Results}

In general, the results shown in Table 1 indicate that the two groups were homogeneous for all parameters (no significant difference between the two groups before learning).In addition, the experimental group shows significant differences between the before and after training and for all tested parameters. Furthermore, significant differences were recorded between the control group and the experimental group at the after training (except the number of errors left and \% Cumulative errors left). Moreover, the Table 1 specify that the progress $(\Delta=$ before - After) recorded by the experimental group is significantly different from the control group at all settings (except the number of errors left and \% Cumulative errors left). The data obtained in the test assessment are analysed among the answers of the participants.

\subsection{Number of Mirrors on the Right}

As regarding the number of mirrors on the right in the results of the test assessment, Figure 1 showed on one

Table 1. Means and standard deviations of the parameters of the study before and after training for both groups.

\begin{tabular}{|c|c|c|c|c|c|c|}
\hline \multirow{2}{*}{ Parameters } & \multicolumn{3}{|c|}{ Control Group (N = 22) } & \multicolumn{3}{|c|}{ Experimental Group (N = 22) } \\
\hline & Before & After & $\Delta(\Delta \%)$ & Before & After & $\Delta(\Delta \%)$ \\
\hline Number of mirror $R$ & $1.36 \pm 0.79$ & $1.27 \pm 0.63$ & $0.09(6.67 \%)$ & $1.32 \pm 0.84$ & 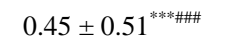 & $0.86(65.52 \%)^{\# \# \#}$ \\
\hline Number of mirror $\mathbf{L}$ & $1 \pm 0.53$ & $0.91 \pm 0.43$ & $0.09(9.09 \%)$ & $1 \pm 0,62$ & 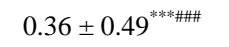 & $0.64(63.64 \%)^{\# \#}$ \\
\hline Number of errors $R$ & $1 \pm 0.98$ & $0.86 \pm 0.89$ & $0.14(13.64 \%)$ & $1.05 \pm 1.21$ & $0.14 \pm 0.35^{* * * \# \#}$ & $0.91(86.96 \%)^{\# \#}$ \\
\hline Number of errors $L$ & $0.32 \pm 0.48$ & $0.23 \pm 0.43$ & $0.09(28.57 \%)$ & $0.5 \pm 0.8$ & $0.05 \pm 0.21^{* *}$ & $0.45(90.91 \%)$ \\
\hline \% Cumulative mirror $\mathbf{R}$ & $15.18 \pm 19.02$ & $15.55 \pm 18.9$ & $-0.36(-2.4 \%)$ & $15.32 \pm 19$ & 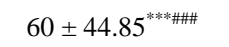 & $-44.68(-291.69 \%)^{\# \# \#}$ \\
\hline \% Cumulative mirror $L$ & $26.91 \pm 29.76$ & $27.27 \pm 29.59$ & $-0.36(-1.35 \%)$ & $27.05 \pm 29.7$ & $69.45 \pm 41.36^{* * * \# \#}$ & $-42.41(-156.81 \%)^{\# \#}$ \\
\hline$\%$ Cumulative errors $\mathbf{R}$ & $34.91 \pm 45.52$ & $39.23 \pm 47.03$ & $-4.32(-12.37 \%)$ & $39.14 \pm 47.1$ & $87.05 \pm 33.37^{* * * \# \#}$ & $-47.91(-122.42 \%)^{\# \#}$ \\
\hline \% Cumulative errors L & $66.36 \pm 42.91$ & $74.55 \pm 38.6$ & $-8.18(-12.33 \%)$ & $66.36 \pm 42.91$ & $90.91 \pm 19.19^{* *}$ & $-24.55(-36.99 \%)$ \\
\hline
\end{tabular}

Note: Source: Own elaboration. "Significant difference compared to the prior learning $p<0.05 ;{ }^{* *} p<0.01 ;{ }^{* * *} p<0.001$. ${ }^{*}$ Significantly different from the control group at $p<0.05 ;{ }^{\#} p<0.01 ;{ }^{\# \#} p<0.001$. 


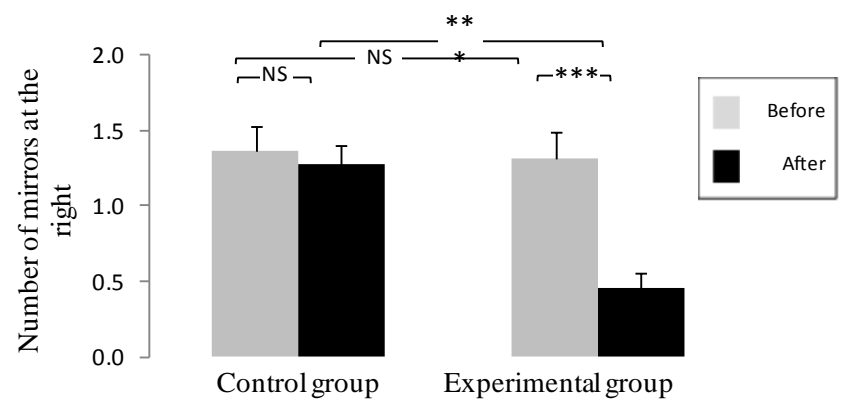

Figure 1. Number of mirrors on the right before and after learning among both groups. NS: not significant $(p>0.05)$; ***Significantly different at $p<0.001$.

hand, a significant group effect $[F(1,42)=5.15 ; p=0.028] ; \eta^{2}=0.109$ and on the other one, a significant learning effect $[F(1,42)=25.65 ; p<0.001] ; \eta^{2}=0.379$. However, group learning interactionis significant $[F(1$, 42) $=16.81 ; p<0.001] ; \eta^{2}=0.286$

\subsection{Number of Mirrors on the Left}

As shown in Figure 2 a significant group effect is noted $[\mathrm{F}(1,42)=4.45 ; p=0.041] ; \eta^{2}=0.096$ concerning the number of mirrors on the left and also a significant learning effect too $[\mathrm{F}(1,42)=16.39 ; p<0.001] ; \eta^{2}=0.28$. As well as, an group learning interaction is significant $[\mathrm{F}(1,42)=9.22 ; p=0.004] ; \eta^{2}=0.18$.

\subsection{Number of Errors on the Right}

As regarding the number of errors on the right, the Figure 3 although it showed a non-significant group effect [F $(1,42)=1.92 ; p=0.173] ; \eta^{2}=0.044$, it presented a significant learning effect $[\mathrm{F}(1,42)=17.77 ; p<0.001] ; \eta^{2}$ $=0.297$ and a significant group learning interaction $[\mathrm{F}(1,42)=9.71 ; p=0.003] ; \eta^{2}=0.188$.

\subsection{Number of Errors on the Left}

As regarding the number of errors on the left in the results of the test assessment, Figure 4 showed a non-significant group effect $[\mathrm{F}(1,42)=0 ; p=1] ; \eta^{2}=0$, but a significant learning effect $[\mathrm{F}(1,42)=9 ; p=0.005] ; \eta^{2}=$ 0.176 and an insignificant group learning interaction $[\mathrm{F}(1,42)=4 ; p=0.052] ; \eta^{2}=0.087$.

\subsection{Cumulative Percentage Mirrors on the Right}

As shown as in the Figure 5, the percentage cumulative mirrors on the right present a significant Group effect $[\mathrm{F}(1,42)=10.41 ; p=0.002] ; \eta^{2}=0.199$. Also, a significant learning effect $[\mathrm{F}(1,42)=22.56 ; p<0.001] ; \eta^{2}=$ 0.349 and a significant group learning interaction $[\mathrm{F}(1,42)=21.84 ; p<0.001] ; \eta^{2}=0.342$.

\subsection{Cumulative Percentage Mirrors on the Left}

As shown in Figure 6 a significant group effect is noted $[F(1,42)=5.75 ; p=0.021] ; \eta^{2}=0.12$ for the percentage cumulative mirrors left, in addition of a significant learning effect $[\mathrm{F}(1,42)=21.68 ; p<0.001] ; \eta^{2}=0.34$ and a significant group learning interaction $[\mathrm{F}(1,42)=20.95 ; p<0.001] ; \eta^{2}=0.333$.

\subsection{Cumulative Errors Percentage on the Right}

Regarding the cumulative errors percentage on the right, the Figure 7 showed asignificant group effect $[\mathrm{F}(1,42)$ $=4.78 ; p=0.034] ; \eta^{2}=0.102$. It presented, furthermore, a significant learning effect $[\mathrm{F}(1,42)=21.66 ; p<$ $0.001] ; \eta^{2}=0.34$ and a significant group learning interaction $[\mathrm{F}(1,42)=15.09 ; p<0.001] ; \eta^{2}=0.264$.

\subsection{Cumulative Errors Percentage on the Left}

Figure 8 announced a non-significant effect group $[F(1,42)=0.74 ; p=0.393] ; \eta^{2}=0.017$ concerning the 


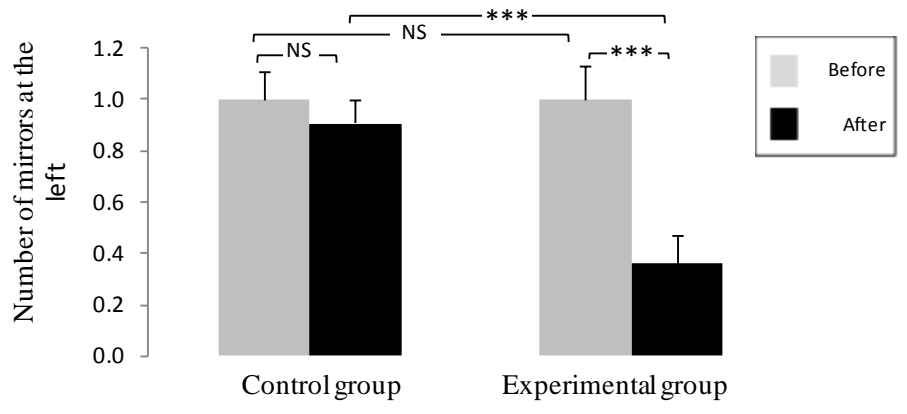

Figure 2. Number of mirrors on the left before and after learning the control group and the experimental group. NS: not significant ( $p>$ $0.05)$; ***significantly different at $p<0.001$.

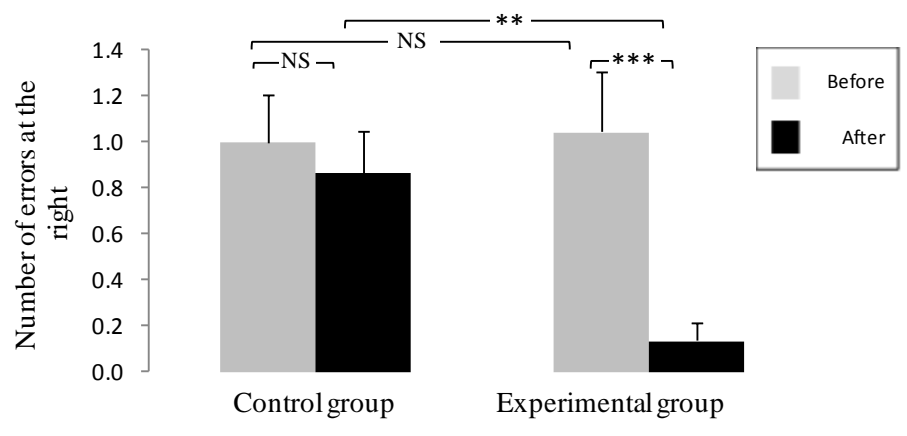

Figure 3. Number of errors on the right before and after learning the control group and the experimental group. NS: not significant ( $p>$ $0.05)$; $* *$ Significant difference at $p<0.01 ; * * * p<0.001$.

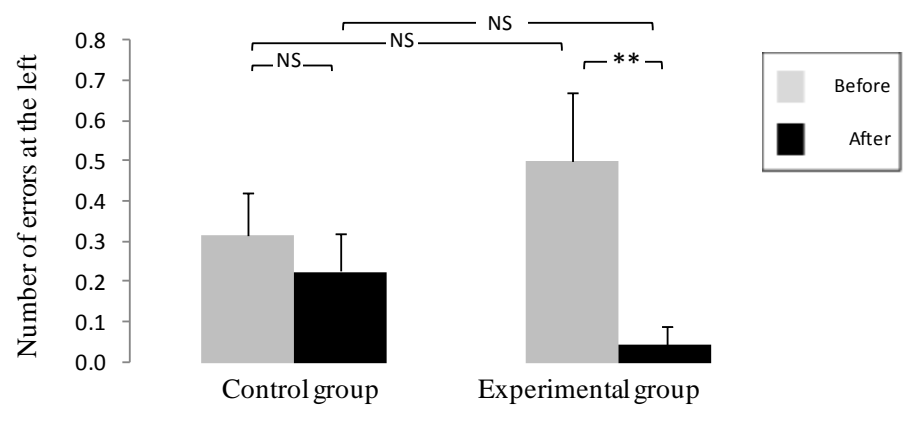

Figure 4. Number of errors on the left before and after learning the control group and the experimental group. NS: not significant $(p>$ $0.05)$;**Significant difference at $p<0.01$.

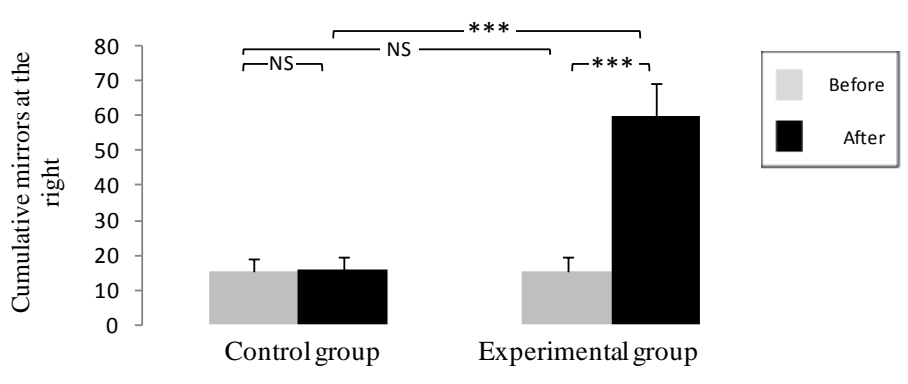

Figure 5. Cumulative percentage mirrors on the right before and after learning the control group and the experimental group. NS: not significant $(p>0.05)$; ***Significantly different at $p<0.001$. 


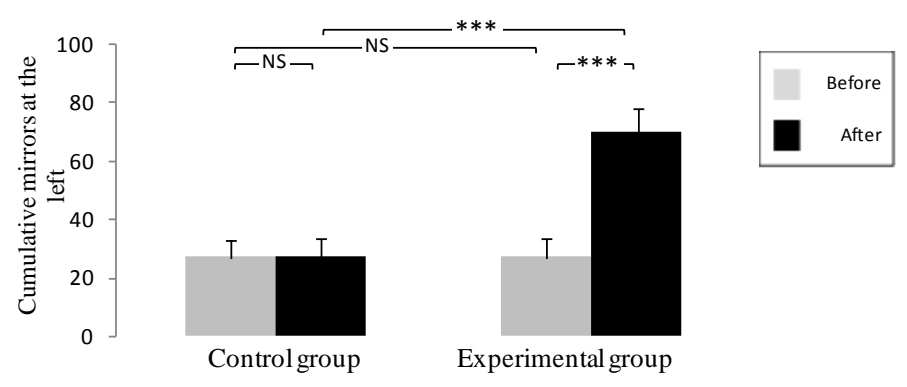

Figure 6. Cumulative Percentage mirrors on the left before and after learning the control group and the experimental group. NS: not significant $(p>0.05)$; ***Significantly different at $p<0.001$.

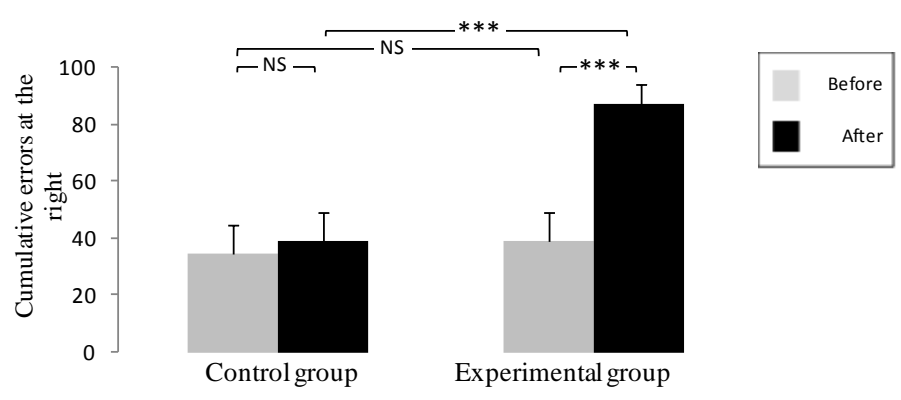

Figure 7. Cumulative errors percentage on the right before and after learning the control group and the experimental group. NS: not significant $(p>0.05) ; * * *$ Significantly different at $p<0.001$.

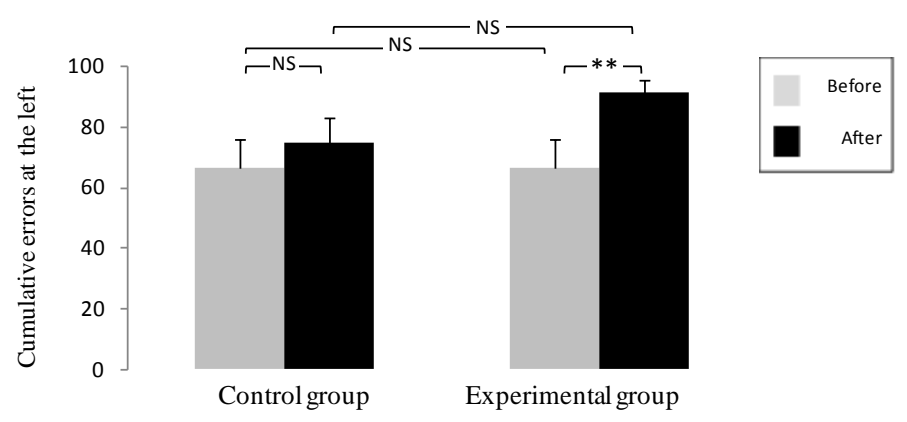

Figure 8. Cumulative errors percentage on the left before and after learning the control group and the experimental group. NS: not significant $(p>0.05)$; **Significant difference at $p<0.01$.

cumulative percentage of errors in the left. Nevertheless it revealed a significant learning effect $[\mathrm{F}(1,42)=7.47$; $p=0.009] ; \eta^{2}=0.151$, contrary the group learning interaction is insignificantly shown $[\mathrm{F}(1,42)=1.87 ; p=$ $0.179] ; \eta^{2}=0.043$.

\section{Discussion}

This study aimed at evaluating the effects of the use of a motor education program based on the game and seeking exploration and location of the space from predefined benchmarks on topological skills of the student.

The results of the study show that students mainly in the experimental group performed better than those who followed a traditional learning. In fact, we found that the learning effect is significant and at all levels of the test (number and percentage cumulative mirrors and errors right and left).

Consistent with many studies, moving is a motor and sensory experience in connection with the memory, for understanding the spatial environment organization (Viader, Eustace, \& Lechevalier, 2000; Bidet-Ildéi, Orliaguet, \& Coello, 2011). To be represented, the space must be experienced as moving in us, we simultaneously 
change our perception of the environment. "The Exchequer points" offers for the student the opportunity to navigate in the game space while seeking his sensory-motor system based in particular on building repositories and egocentric allocentrics that working together or separately, conduct ongoing updating of its own "mapping” extracorporeal and directional competence (left-right). The purpose of these systems is to allow the taking of benchmarks and the construction of a "space of places" in which objects are identified and located as the target of the action (Paillard, 1991).

Many other researches (Thommen \& Rimbert, 2005; Pêcheux, 1990; Pradet et al., 1982) were then agreed that the spatial language can only develop through mental and cognitive representations related to the arrangement of the environment. Spelke \& Shusterman (2005) assume that the acquisition of a natural spatial language has to be combined with some different areas of our knowledge of space.

However, the game changes the zone of proximal development. Apprenticeships located in this area are oriented towards a level of cognitive development processes that the child has not yet acquired, but which becomes accessible with a pair support, a parent or a teacher. Thus, among Vygotsky, learning by the game is a good learning because it precedes the development (Rivière, 1990). In this perspective, it seems legitimate to ask once again this question: A pedagogy which has the ambition to bring children beyond the game in their learning shouldn't be started particularly from the game?

The research findings, although of a limited validity and generalization due to the small size of the sample, showed that motor game "exchequer points" can play an important role in the learning of fundamental concepts relating to the topological structure of the relational space and which are also offered for cross thematic and interdisciplinary teaching in school education skills like Mathematics, fine art education, handwriting and eventually other disciplines.

\section{References}

Aleman, A., Schutter, D. J., Ramsey N.F., Van Honk, J., Kessels, R. P., Hoogduin J.M, Postma, A., Kahn, R. S., \& Haan, E. H. (2002). Functional Anatomy of Top-Down Visuospatial Processing in the Human Brain: Evidence from TMS. Cognitive Brain Research, 14, 300-302. http://dx.doi.org/10.1016/S0926-6410(02)00109-X

Barisnikov, K., \& Pizzo, R. (2007). Examination of Visuo-Spatial Competances. In M.-P. Noël (Ed.), Neuropsychological Assassurent of Children (pp. 139-170). Wavre: Mardaga.

Barry, V. (2010). Test of Topological and Directional Relationship. RTD Lacertrecalibration 2010, http://www.geppe.free.fr/article.php3?id_article=265,published26/11/2010

Bidet-Ildéi, C., Orliaguet, J. P., \& Coello, Y. (2011). Role of Motor Representations in the Identification of Human Movement. Psychological Year, 111, 409-445.

Darling, W. G., \& Miller, G. F. (1995). Perception of Arm Orientation in Three-Dimensional Space. Experimental Brain Research, 102, 495-502. http://dx.doi.org/10.1007/BF00230653

Doré, F., \& Mercier, P. (1992). The Foundations of Learning and Cognition. Lille: University Publications Lille, Gaëtan Morin.

Fayasse, M., \& Thibaut, J.P. (2003). Cognitive Disorders in Visuo-Constructives Williamssyndrome. Psychological Year, 104, 695-727.

Felleman, D. J., \& Van Essen, D. C. (1991). Distributed Hierarchical Processing in Primate Visual Cortex. Cerebral Cortex, 1, 1-47. http://dx.doi.org/10.1093/cercor/1.1.1

Gärling, T. (1995). How Do Urban Residents Acquire, Mentally Represent, and Use Knowledge of Spatial Layout? In T. Gärling (Eds.), Readings in Environmental Psychology: Urban Cognition (pp. 1-12). London: Academic Press.

Gärling, T., Book, A., \& Lindberg, E. (1984). Cognitive Mapping of Large Scale Environments: The Interrelationships of Action Plans, Acquisition and Orientation: Environment and Behavior, 16, 3-34. http://dx.doi.org/10.1177/0013916584161001

Ghafouri, M., Archambault, P. S., Adamovich, S. A., \& Feldman, A. G. (2002). Pointing Movements May Be Produced in Different Frames of Reference Depending on the Task Demand. Brain Research, 929, 117-128.

http://dx.doi.org/10.1016/S0006-8993(01)03332-7

Gibson, J. J. (1979). The Ecological Approach to Visual Perception. Boston, MA: Houghton Mifflin.

Ginsburg, K. R. (2007). The Importance of Play in Promoting Healthy Child Development and Maintaining Strong ParentChild Bonds. Pediatrics, 119, 182-191. http://dx.doi.org/10.1542/peds.2006-2697

Goodale, M. A., \& Milner, A. D. (1992). Separate Visual Pathways for Perception and Action. Trends in Neuroscience, 15, 


\section{0-25. http://dx.doi.org/10.1016/0166-2236(92)90344-8}

Jeannerod, M. (1994). The Representing Brain: Neural Correlates of Motor Intention and Imagery. Behavioral and Brain Sciences, 17, 187-245. http://dx.doi.org/10.1017/S0140525X00034026

Jeannerod, M. (2003). Consciousness of Action and Self-Consciousness: A Cognitive Neuroscience Approach. In J. Roessler, \& N. Eilan (Eds.), Agency and Self-Awareness: Issues in Philosophy and Psychology (pp. 128-149). Oxford: Oxford University Press.

Jeannerod, M. (2006). Motor Cognition. Oxford: Oxford University Press. http://dx.doi.org/10.1093/acprof:oso/9780198569657.001.0001

Jeannerod, M., \& Biguer, B. (1987). The Directional Coding of Reaching Movements: A Visuomotor Conception of Spatial Neglect. In M. Jeannerod (Ed.), Neurophysiological and Neuropsychological Aspects of Spatial Neglect (pp 87-113). Amsterdam: Elsevier.

Karn, K. S., Moller, P., \& Hayhoe, M. M. (1997). Reference Frames in Saccadic Targeting. Experimental Brain Research, 115, 267-282. http://dx.doi.org/10.1007/PL00005696

Lester, S. (2011). The Pedagogy of Play, Space and Learning. In A. Pihlgren (Ed.), Fritidspedagogik (pp. 115-138). Lund: Sutdentlitteratur.

Marr, D. (1982). Vision: A Computational Investigation into the Human Representation and Processing of Visual Information. New York: W.H. Freeman.

Milner, A. D., \& Goodale, M. A. (1995). The Visual Brain in Action. Oxford: Oxford Press.

Mossio, M., \& Taraborelli, D. (2008). Action-Dependent Perceptual Invariants: From Ecological to Sensorimotor Approaches. Consciousness and Cognition, 17, 1324-1340. http://dx.doi.org/10.1016/j.concog.2007.12.003

Neggers, S. F., \& Bekkering, H. (2000). Ocular Gaze Is Anchored to the Target of an Ongoing Pointing Movement. Journal of Neurophysiology, 83, 639-651.

Noordzij, M. L., \& Postma, A. (2005). Categorical and Metric Distance Information in Mental Representations Derived from Route and Survey Descriptions. Psychological Research, 69, 221-232. http://dx.doi.org/10.1007/s00426-004-0172-y

O’keefe, J., \& Nadel, L. (1976). The Hippocampus as a Cognitive Map. Oxford: Claredom Press.

Paillard, J. (1991). Motor and Representational Framing of Space. In J. Paillard (Ed.), Brain and Space (pp. 163-182). Oxford: Oxford University Press.

Paoletti, R. (1999). Education and Motricity, Case of Two to Eight Aged Childs. Québec: Gaëtan Morin Editor.

Pêcheux, M. G. (1990). The Development of Children Relationship with Space. Poitiers: Nathan.

Péruch, P., Chabanne, V., Nese, M. P., Thinus-Blanc, C., \& Denis, N. (2006). Comparing Distances in Mental Images Constructed from Visual Experience or Verbal Descriptions: The Impact of Survey versus Route Perspective. Quarterly Journal of Experimental Psychology, 59, 1950-1967. http://dx.doi.org/10.1080/17470210500539408

Pierre, P., \& Soppelsa, R. (1998). Clinical Evaluation of Disorder in Great Outdoors Spaces. Psychomotors Evolutions, 10, 205-216.

Pradet, M., De Agostini, M., \& Zazzo, R. (1982). Ground Track, Spatial Structuring Test. Childhood, 1, 61-74.

Previc, F. H. (1998). The Neuro Psychology of 3D Space. Psychological Bulletin, 124, 123-124.

Rao, R. P. N., \& Ballard, D. H. (1999). Predictive Coding in the Visual Cortex: A Functional Interpretation of Some Extra-Classical Receptive Field Effects. Nature Neuroscience, 2, 79-87. http://dx.doi.org/10.1038/4580

Rivière, A. (1990). The Psychology Vygotsky. Liège: Pierre Mardaga.

Russell, J. A., \& Ward, L. M. (1982). Environmental Psychology. Annual Review of Psychology, 33, 651-688. http://dx.doi.org/10.1146/annurev.ps.33.020182.003251

Scannell, J. W., \& Young, M. P. (1999). Primary Visual Cortex within the Cortico-Cortico-Thalamic Network. In: A. Peters, E. G. Jones, \& B. R. Payne (Eds.), Cerebral Cortex, Vol. 15. Cat Primary Visual Cortex. New York: Plenum.

Soechting, J. F., \& Terzuolo, C. A. (1990). Sensorimotor Transformations and the Kinematics of Arm Movements in ThreeDimensional Space. In M. Jeannerod, \& N. J. Hillsdale (Eds.), Attention and Performance 13: Motor Representation and Control (pp. 479-494). Hove, UK: Lawrence Erlbaum Associates, Inc.

Spelke, E., \& Shusterman, A. (2005). Language and the Development of Spatial Reasoning. In P. Carruhers, S. Laurence, \& S. Stich (Eds.), The Innate Mind: Structure and Contents (pp. 89-105) Oxford: Oxford University Press.

Thommen, E., \& Rimbert, G. (2005). The Child and the Knowledge of Others (pp. 59-80). Paris: Belin.

Tolman, E. C. (1948). Cognitive Maps in Rats and Men. Psychological Review, 55, 189-208.

http://dx.doi.org/10.1037/h0061626 
Tucker, P. (2008). The Physical Activity Levels of Preschool-Aged Children: A Systematic Review. Early Childhood Research Quarterly, 23, 547-558. http://dx.doi.org/10.1016/j.ecresq.2008.08.005

Ungerleider, L. G., Courtney, S. M., \& Haxby, J. V. (1998). A Neural System for Human Visual Working Memory. Proceedings of the National Academy of Sciences, 95, 883-890. http://dx.doi.org/10.1073/pnas.95.3.883

Ungerleider, L., \& Mishkin, M. (1982). Two Cortical Visual Systems. In D. Ingle, M. Goodale, \& R. Mansfield (Eds.), Analysis of Visual Behavior (pp. 549-586). Cambridge: MIT Press.

Viader, F., Eustache, F., \& Lechevalier, B. (2000). Espace, Geste, Action. Bruxelles: De Boeck Université.

Wade, N. J., \& Swanston, M. (2001). Visual Perception: An Introduction (2nd ed.). London: Psychology Press.

Wauters-Krings, F. (2009). Preschool Psychomotricity. The Driving Situations at the Service of the Child's Development. Bruxelles: De Boeck Université.

Wohlwill, J. F. (1981). A Conceptual Analysis of Exploratory Behavior. In H. I. Day (Ed.), Advances in Intrinsic Motivation and Aesthetics (pp. 385-414). New York: Plenum Press.

Young, M. P. (2000). The Architecture of Visual Cortex and Inferential Processes in Vision. Spatial Vision, 13, $137-146$. http://dx.doi.org/10.1163/156856800741162 